\title{
The Role of Cytology in the Diagnosis of Metastatic Hepatocellular Carcinoma
}

\author{
Jui-Chung Wang ${ }^{1}$, Jui-Ting $\mathrm{Hu}^{2}$ and Chih-Yu Hsu ${ }^{1, *}$ \\ 1 Division of Chest Medicine, Department of Internal Medicine, Cathay General Hospital, Taipei 10651, Taiwan; \\ garnet0511.tw@yahoo.com.tw \\ 2 Liver Center, Department of Internal Medicine, Cathay General Hospital, Taipei 10651, Taiwan; \\ huyeh0203@gmail.com \\ * Correspondence: cgh00498@cgh.org.tw
}

Citation: Wang, J.-C.; Hu, J.-T.; Hsu, C.-Y. The Role of Cytology in the Diagnosis of Metastatic Hepatocellular Carcinoma. Reports 2021, 4, 20. https://doi.org/10.3390/ reports 4030020

Academic Editor: Ivana Kholová

Received: 12 May 2021

Accepted: 27 June 2021

Published: 30 June 2021

Publisher's Note: MDPI stays neutral with regard to jurisdictional claims in published maps and institutional affiliations.

Copyright: (c) 2021 by the authors. Licensee MDPI, Basel, Switzerland. This article is an open access article distributed under the terms and conditions of the Creative Commons Attribution (CC BY) license (https:/ / creativecommons.org/licenses/by/ $4.0 /)$.

\begin{abstract}
The diagnosis of primary hepatocellular carcinoma (HCC) in high risk patients, such as those with chronic hepatitis B or C with/without cirrhosis of the liver, can be made with relevant image studies alone; however, morphologic confirmation by cytology or histopathology is essential to the diagnosis of metastatic HCC because the treatment of the latter differs from that of primary extrahepatic malignancy. Although both cytology and histopathology are important tools in the diagnosis of malignancy, histopathology almost always plays a confirmatory and pivotal role, and also a gold standard in cyto-histological correlation. We present two patients of metastatic HCC to rare sites; endobronchus in one, and neck lymph nodes, face and the abdominal wall in the other. Repeated bronchial biopsy in the first patient and excisional biopsy from the metastatic sites of the second patient failed to make a conclusive diagnosis of metastatic HCC. However, bronchial brushing in the first patient and fine needle aspiration cytology from the respective metastatic sites of the second patient consistently showed characteristic HCC features and provided clinicians with the rationale for ongoing treatment. The diagnostic issues and possible pitfalls are discussed. Cytology and histopathology appear equipollent; sometimes cytology can play a diagnostic role when histopathology fails its expected role in this scenario.
\end{abstract}

Keywords: cytology; metastatic hepatocellular carcinoma; endobronchus; neck lymph node; face; abdominal wall; cyto-histological correlation

\section{Introduction}

Hepatocellular carcinoma (HCC) is the main malignancy of the liver. Metastatic HCC can be found elsewhere in the body, such as in the lung, lymph nodes, bone, and the adrenal gland. Although the diagnosis of primary HCC in high risk patients, such as those with chronic hepatitis B or C with/without cirrhosis of the liver, can be made with relevant image studies alone [1], morphologic confirmation by histopathology or cytology is essential to the diagnosis of metastatic HCC because the treatment of the latter differs from that of a concurrent primary extrahepatic malignancy.

Both cytology and histopathology are important tools in the diagnosis of malignancy. Taking advantage of preserved tissue architecture with various kinds of adjuvant immunohistochemistry (IHC), histopathology almost always plays a confirmatory and pivotal role in the diagnosis of malignancy. Furthermore, histopathology is also considered a measure of quality assurance of the performance of cytology by cyto-histopathology correlation in the laboratory.

We present two patients of HCC with extrahepatic metastasis to rare sites; that is, the endobronchus in one patient, and the neck lymph node, face and abdominal wall in the other. Histopathology by repeated bronchoscopic biopsy in the first patient and excisional biopsy from the respective metastatic sites of the second patient unexpectedly failed to make a conclusive diagnosis of metastatic HCC. On the other hand, bronchial brushing 
in the first patient and fine needle aspiration (FNA) cytology from the respective tumor sites of the second patient consistently showed characteristic HCC features and provided clinicians with the rationale for ongoing treatment.

\section{Case Reports}

A 57-year-old man, a chronic hepatitis B carrier with cirrhosis of the liver, was found to have a new $4.5 \times 3.6 \mathrm{~cm}^{2}$ tumor in his right middle lung on chest radiograph in 6 months. He was diagnosed to have HCC about 19 months earlier with serum $\alpha$-fetoprotein (AFP) being $8.0 \mathrm{ng} / \mathrm{mL}$ (normal $<20 \mathrm{ng} / \mathrm{mL}$ ). He had been treated with various modalities, including transarterial chemoembolization with adriamycin-lipiodol emulsion, radiofrequency ablation, tryrosine kinase inhibitor (sorafenib), systemic chemotherapy (doxorubicin) and radiotherapy. A bronchoscopy disclosed a tumor covered with necrotic material at the orifice of right middle lobe (RML) (Figure 1).

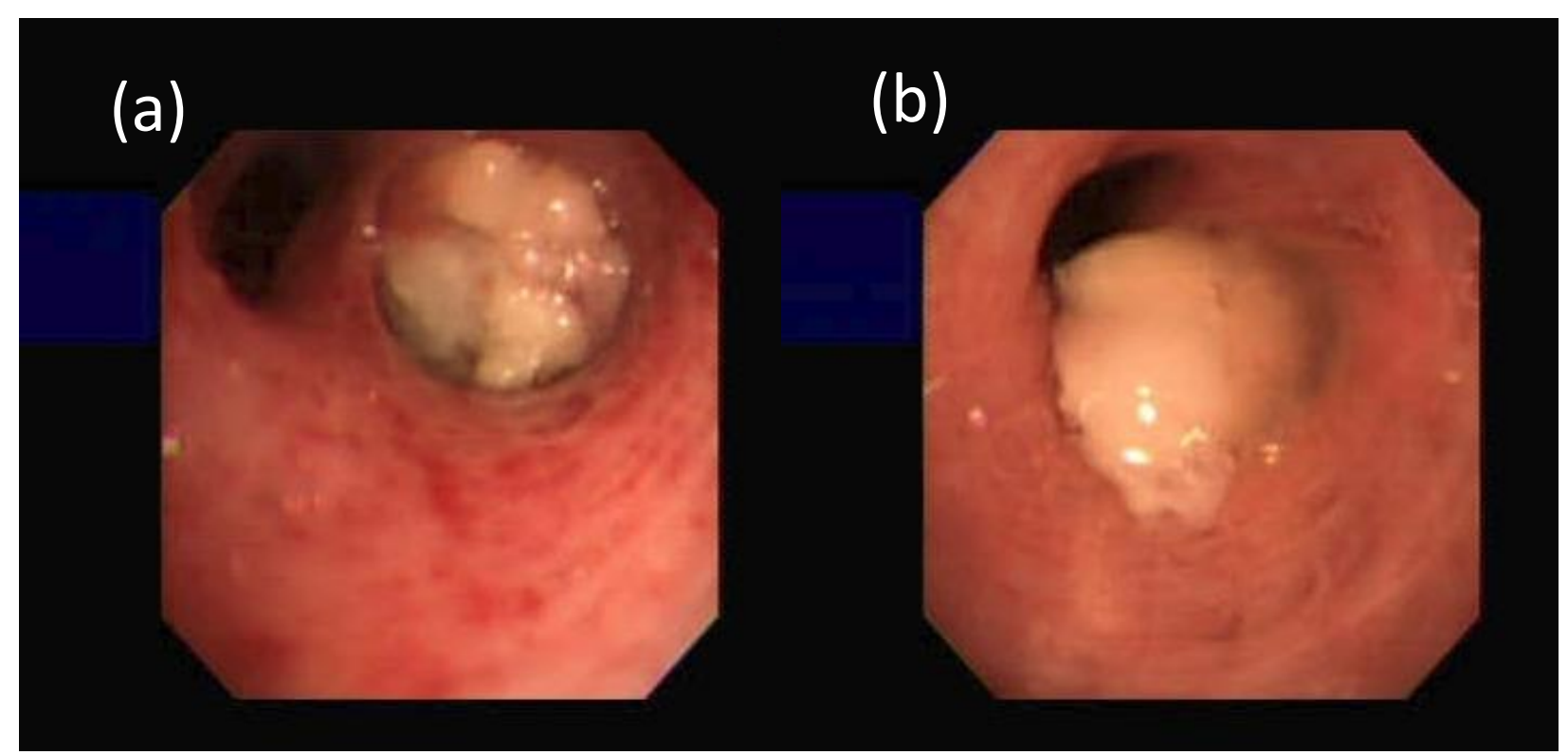

Figure 1. Bronchoscopy of the first patient (a) at first and (b) three weeks later showing a tumor at the orifice of right middle lobe covered with necrotic material.

Bronchial brushing cytology showed tumor cells with polygonal outline and welldefined borders, central nuclei and granular cytoplasm with high nuclear/cytoplasmic $(\mathrm{N} / \mathrm{C})$ ratios (Figure 2).

However, a bronchoscopic biopsy showed tumor cells with necrosis. Repeated bronchoscopy three weeks later showed the tumor covered with necrotic material at the orifice of the RML and protruding into the distal part of the truncus intermedius (Figure 1). Bronchial brushing cytology showed the same findings as the previous one. The bronchoscopic biopsy showed carcinoma cells with canalicular pattern and necrosis. IHC studies (Table 1) were negative for hepatocyte paraffin 1 (Hep Par-1), AFP, glypican 3, cytokeratin (CK) 7, CK 20, and thyroid transcription factor 1 (TTF-1) but equivocally positive for p40 antibody, p63 and polyclonal carcinoembryonic antigen (CEA) and CD 10 rare and equivocal. His serum CEA titer was $4.0 \mathrm{ng} / \mathrm{mL}$ (normal $<5.0 \mathrm{ng} / \mathrm{mL}$ ). The lung tumor reduced markedly in two months after sorafenib and local radiation therapy but rebounded three months later with no further continuation of the treatment. The patient developed subsequently many large nodules varying from $2 \mathrm{~cm}$ to $4 \mathrm{~cm}$ in both lungs and massive right pleural effusion. The pleural fluid CEA titer was $2.1 \mathrm{ng} / \mathrm{mL}$ with negative results for cytology and cell block. Follow-up abdominal tomography 6 months later showed no increase of the liver tumors (Figure 3a); however, the follow-up abdominal tomography two years and one month after the bronchoscopy showed several new viable HCCs in the lateral 
segment (Figure $3 \mathrm{~b}$ ) and a persistent truncated right portal vein, probably due to tumor compression or thrombosis. Finally, he died of massive gastrointestinal bleeding 49 months after initial diagnosis. His serum AFP had been steadily rising up to $18,350 \mathrm{ng} / \mathrm{mL}$ over the past 4 years.

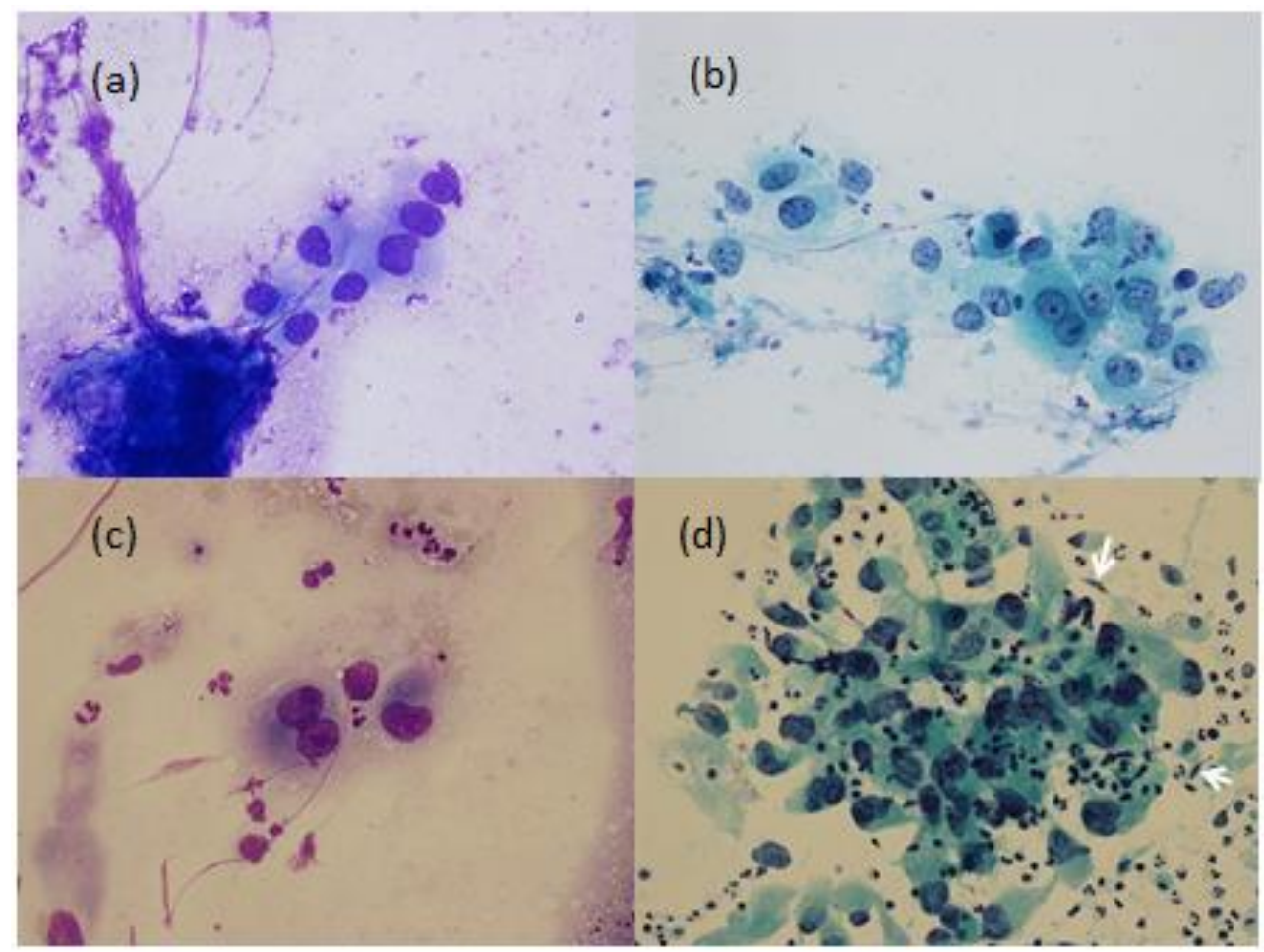

Figure 2. Bronchial brushing cytology $(\mathbf{a}, \mathbf{b})$ in Patient 1 and fine needle aspiration cytology of cervical lymphadenopathy (c,d) in Patient 2. Note that tumor cells with polygonal outline, central nuclei, high $\mathrm{N} / \mathrm{C}$ ratio, irregular nuclear membrane, prominent nucleoli, $(\mathbf{a}-\mathbf{c})$ trabecular pattern and endothelial cells with elongated nucleus (white arrows) (d) were observed. (left panels Liu's stain [2] equivalent to Diff-Quick stain or Giemsa stain; right panels Papanicolaou stain; $400 \times$ ).

Table 1. Summary of the immunohistochemistry studies of these two patients.

\begin{tabular}{|c|c|c|c|c|c|c|c|c|c|c|c|}
\hline $\begin{array}{c}\text { Sample } \\
\text { Specimen }\end{array}$ & $\begin{array}{c}\text { Tumor } \\
\text { Necrosis }\end{array}$ & Hep-Par 1 & TTF -1 & $\mathrm{p} 40$ & $\begin{array}{c}\text { CK } 7 \text { and } \\
\text { CK } 20\end{array}$ & p63 & GATA 3 & CD 10 & AFP & Glypican 3 & $\begin{array}{l}\text { Polyclonal } \\
\text { CEA }\end{array}$ \\
\hline $\begin{array}{c}\text { Bronchoscopic } \\
\text { biopsy } 1^{*}\end{array}$ & present & $(-)$ & $(-)$ & $( \pm)$ & $\begin{array}{l}\text { occasionally } \\
\text { positive }\end{array}$ & ND & ND & ND & ND & ND & ND \\
\hline $\begin{array}{l}\text { Bronchoscopic } \\
\text { biopsy } 2^{f}\end{array}$ & focal & $(-)$ & $(-)$ & $( \pm)$ & $(-)$ & $( \pm)$ & ND & $\begin{array}{l}\text { rare, } \\
( \pm)\end{array}$ & $(-)$ & $(-)$ & $( \pm)$ \\
\hline $\begin{array}{c}\text { Left neck } \\
\text { lymph node }\end{array}$ & present & $\begin{array}{l}\text { focal, and } \\
\text { weak }\end{array}$ & $(-)$ & ND & $(+)$ & ND & $\begin{array}{l}\text { focal, and } \\
\text { weak }\end{array}$ & ND & ND & ND & ND \\
\hline
\end{tabular}

${ }^{*}$ Initial bronchoscopy of Patient $1 ;{ }^{\dagger}$ Bronchoscopic biopsy three weeks after the initial bronchoscopy of Patient 1 ; ${ }^{\ddagger}$ Left neck lymph node biopsy: Patient 2; $(+)$ : positive; $( \pm)$ : equivocal; $(-)$ : negative; ND: not done; for abbreviations of the tumor markers please refer to the text.

The second patient, a 74-year-old man with chronic hepatitis B and cirrhotic liver, had an enlarged left lower neck lymphadenopathy for 1 week. He had advanced HCC status after several therapies for more than 52 months. Abdominal echography showed the diameter of the main portal vein was $1.0 \mathrm{~cm}$. There was a hyperechoic tumor at segment 3 and a mixed-echoic tumor at segment $6 / 7$. FNA of the lymphadenopathy showed the characteristic cytologic findings of HCC (Figure 2). However, the lymph node biopsy could only show tumor necrosis, marked nuclear pleomorphism and focal gland-like spaces. Although IHC studies were positive for CK 7 and CK 20, focal and weak expression for Hep Par-1 and GATA 3 transcription factor, and negative for TTF-1, they were difficult to conclusively determine the primary site of the tumor. Despite the pathologic report, 
he had been continuously treated as HCC with various modalities, including tyrosine kinase inhibitor, local irradiation therapy and immuno-oncology therapy by nivolumab. The reduced size of the neck lymphadenopathy reflected the treatment. However, he had a tumor in the right lower abdominal wall and left face 4 months later. FNA cytology from the respective extrahepatic tumor sites showed consistent features of HCC. Follow-up abdominal echography one year and three months later showed the diameter of the main portal vein was $1.2 \mathrm{~cm}$., a hyperechoic tumor $(1 \mathrm{~cm})$ at segment $2 / 3$ and a mixed-echoic tumor $(3 \mathrm{~cm})$ at segment 5 .

His serum AFP levels have been fluctuating from $22.2 \mathrm{ng} / \mathrm{mL}$ in the beginning and up to $529.8 \mathrm{ng} / \mathrm{mL}$ over the past 3.5 years.

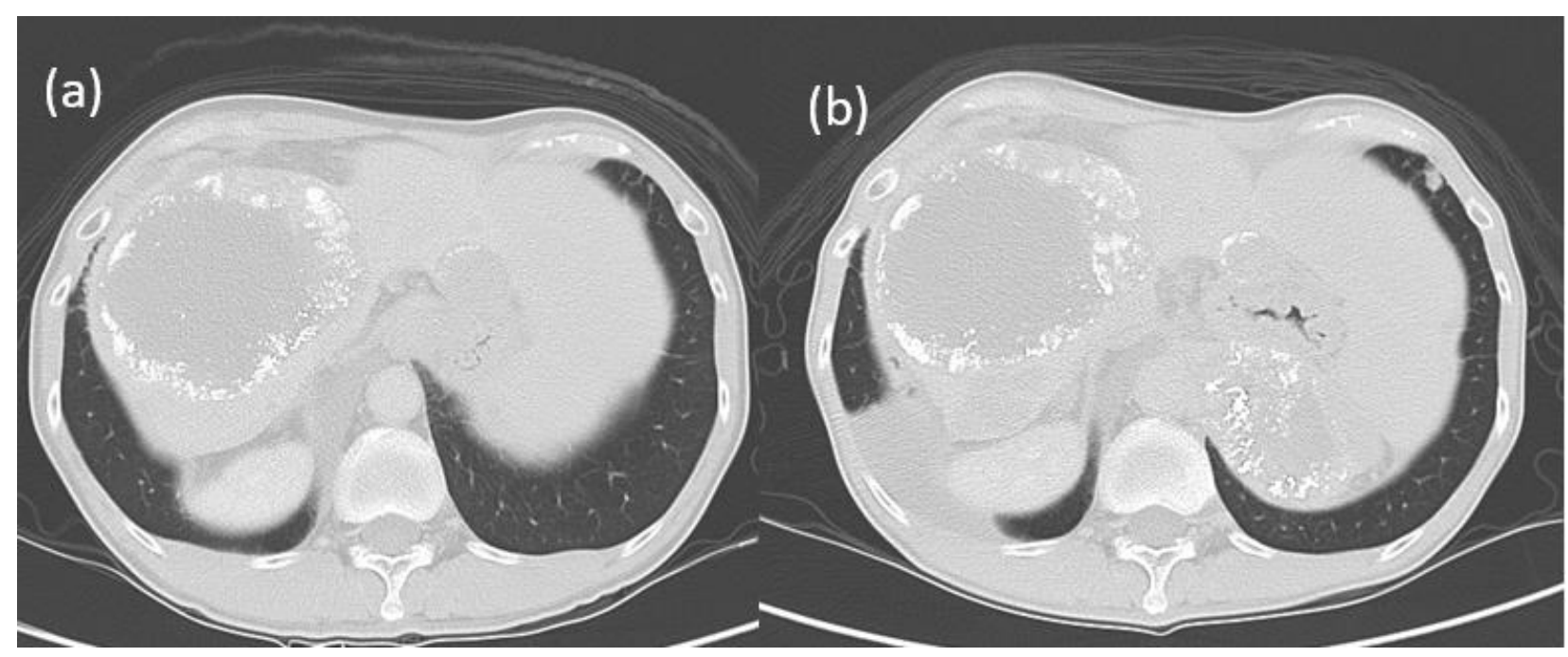

Figure 3. Abdominal tomography of Patient 1 (a) six months after bronchoscopy (b) two years and one month later showing two new liver tumors and a new, small nodule in the anterior aspect of the left lower lung.

\section{Discussion}

Diagnosis of malignancy is made primarily by morphologic studies such as cytology or histopathology. Histopathology studies the morphologic changes of the tumor at tissue level where a preserved tissue architecture is essential for correct interpretation. A tumor specimen without preserved tissue architecture, due to necrosis or crushed artifact, is difficult or even impossible to interpret.

Furthermore, the diagnosis of extrahepatic metastasis of HCC is usually based on the histopathology of the target specimen. Although HCC-specific markers (IHC) such as AFP, polyclonal antisera to CEA (pCEA), Hep Par1 and many others have been introduced to increase the diagnostic accuracy [3-6], these IHCs are, after all, ancillary [3] because they are neither $100 \%$ sensitive nor $100 \%$ specific [3-6]. A negative result of a given HCC-specific IHC in a target extrahepatic tumor cannot exclude the possibility of a metastatic HCC; nor does a positive expression indicate a hepatic origin. Rather, a close clinicopathologic correlation is usually mandatory for the final diagnosis of metastatic HCC [3,4].

In fact, diagnostic image studies and serial changes of HCC-specific tumor markers have been most commonly adopted as diagnostic alternatives to histopathology [4]. Diagnostic imaging studies include abdominal ultrasonography, computed tomography, magnetic resonance imaging, chest radiography or bone scintigraphy. On the other hand, an increase in HCC-specific tumor titer that could not be explained by the status of the intrahepatic lesion imaging was correlated with the diagnosis of metastatic HCC $[3,4]$. Moreover, both of our patients showed their tumor burden. However, it is noteworthy that the given extrahepatic tumors in these patients cannot be well extrapolated to be metastatic HCC solely by their tumor burden. Rather, further investigations are still needed for which morphologic confirmation is the way. 
The cytology of classic HCC is characterized by malignant cells that look like hepatocytes, i.e., large, polygonal cells, granular cytoplasm, central nuclei with irregular nuclear membranes, high N/C ratio, dense and granular chromatin, and sometimes prominent nucleoli [7]. Furthermore, clusters of trabecular growth partially lined by endothelial cells with elongated nuclei are the rule in HCC [7] (pp. 1028-1029).

In the first patient, a concurrent primary lung cancer or a rare site of metastasis from the previous HCC should be clarified before planning ongoing treatment. Despite non-conclusion after repeated bronchoscopic biopsies, the results of bronchial brushing cytology (Figure 2) are in accordance with the above characteristic features of HCC [7] and can support the diagnosis of metastatic HCC.

In the second patient, the characteristic features of FNA cytology (Figure 2.) with the additional characteristic clusters of trabecular growth partially lined by endothelial cells with elongated nuclei [7] (pp. 1028-1029) also support the diagnosis of metastatic HCC even in the absence of confirmative histopathology.

The pitfalls that the histopathology of our patients failed to make a diagnosis of metastatic HCC are multifactorial, including a lack of distinct tissue pattern, equivocal, confusing or inconclusive IHC expressions and tumor necrosis (Figure 1) in the biopsied samples. However, based on the following clinical features, it is justified in drawing a conclusion that these two patients had actually extrahepatic metastatic HCC rather than concurrent extrahepatic primary tumors. First, their serum AFP levels were steadily increasing. Second, their extrahepatic tumors responded well by reducing the tumor size after further HCC-specific treatment. Third, normal serum and pleural effusion CEA levels and negative pleural fluid cytology and cell block in the first patient failed to justify a coexisting primary lung cancer. Last, but not least, the consistent cytologic features from the respective extrahepatic sites were foreign to those of the presumed primary malignancy but were characteristic of HCC [7]; thus, rendering a diagnosis of metastatic HCC.

HCC with metastases to the endobronchus [8-10], neck lymph node [11,12], the face [13] and the abdominal wall [14] are indeed very rare and are in fact anecdotal case reports. These reports were diagnosed by histopathologic studies including HCC-specific IHCs. On the other hand, in this report, our patients were diagnosed by characteristic and consistent cytologic findings, together with clinical correlation. The results provided the clinicians with the rationale for ongoing treatment, even in the absence of confirmative histopathology.

In conclusion, it appears that cytology and histopathology are equipollent and that the characteristic cytologic features, together with clinical correlation in our patients, can play a diagnostic role in the diagnosis of metastatic HCC when histopathology fails its expected role in this scenario.

This work was presented in part in oral form at the annual meeting of Taiwan Society of Clinical Cytology in Taipei, Taiwan on 2 December 2018.

Author Contributions: J.-C.W., performance of bronchoscopy, shared opinion and approval of the manuscript; J.-T.H., work up the patient and the care, shared opinion and approval of the manuscript; C.-Y.H., interpretation of cytologic smears, design and writing the manuscript. All authors have read and approved the submitted manuscript.

Funding: This research received no external funding.

Institutional Review Board Statement: The study was conducted according to the guidelines of the Declaration of Helsinki, and approved by the Institutional Review Board of the Cathay General Hospital (CGH-P108077 approved on 12 August 2019).

Informed Consent Statement: Waived and was approved by the Institutional Review Board of the Cathay General Hospital (CGH-P108077 approved on 12 August 2019).

Data Availability Statement: Not applicable.

Acknowledgments: We thank our cytotechnologist colleagues in cytology laboratory Tse-Chang Chen, Che-Bin Chang, Yen-Chun Liu, and Hsiao-Ping Wang for their work and assistance in cytopreparation. 
Conflicts of Interest: The authors declare no conflict of interest.

\section{References}

1. Marrero, J.A.; Kulik, L.M.; Sirlin, C.B.; Zhu, A.X.; Finn, R.S.; Abecassis, M.M.; Roberts, L.R.; Heimbach, J.K. Diagnosis, Staging, and Management of Hepatocellular Carcinoma: 2018 Practice Guidance by the American Association for the Study of Liver Diseases. Hepatology 2018, 68, 723-750. [CrossRef] [PubMed]

2. Hsu, C.-Y.; Chen, T.-C.; Chang, C.-B.; Liu, Y.-C.; Lin, T.-R. Rehydration before wet fixation in conventional body fluid cytology-An 18-year experience. Cytopathology 2018, 29, 179-183. [CrossRef] [PubMed]

3. Wee, A. Diagnostic Utility of Immunohistochemistry in Hepatocellular Carcinoma, its Variants and Their Mimics. Appl. Immunohistochem. Mol. Morphol. 2006, 14, 266-272. [CrossRef]

4. Kanda, M.; Tateishi, R.; Yoshida, H.; Sato, T.; Masuzaki, R.; Ohki, T.; Imamura, J.; Goto, T.; Yoshida, H.; Hamamura, K.; et al. Extrahepatic metastasis of hepatocellular carcinoma: Incidence and risk factors. Liver Int. 2008, 28, 1256-1263. [CrossRef]

5. Brunt, E.M. Histopathologic features of hepatocellular carcinoma. Clin. Liver Dis. 2012, 1, 194-199. [CrossRef]

6. Nguyen, T.; Phillips, D.; Jain, D.; Torbenson, M.; Wu, T.-T.; Yeh, M.M.; Kakar, S. Comparison of 5 Immunohistochemical Markers of Hepatocellular Differentiation for the Diagnosis of Hepatocellular Carcinoma. Arch. Pathol. Lab. Med. 2015, 139, 1028-1034. [CrossRef] [PubMed]

7. DeMay, R.M. Chapter 23 Liver. In The Art and Science of Cytopathology; American Society of Clinical Pathologists Press: Chicago, IL, USA, 1996; pp. 1017-1052.

8. Sørensen, J.B. Endobronchial metastases from extrapulmonary solid tumors. Acta Oncol. 2004, 43, 73-79. [CrossRef] [PubMed]

9. Braman, S.S. Endobronchial Metastasis. Arch. Intern. Med. 1975, 135, 543-547. [CrossRef] [PubMed]

10. Purandare, N.C.; Pramesh, C.S.; Rangarajan, V.; Shet, T.; Shukla, P.J.; Mistry, R.C. Hepatocellular Carcinoma Recurring as Isolated Endobronchial Metastasis 8 Years After Primary Surgery. J. Thorac. Imaging 2009, 24, 147-149. [CrossRef]

11. Zhao, Z.; Maia, J.; Zhang, X.; Yan, H.; Chen, X.; Liu, X. A Case Report on the Right Cervical Lymph Node Metastasis of Hepatocellular Carcinoma. J. Cancer Sci. Ther. 2018, 10, 329-331. [CrossRef]

12. Madabhavi, I.; Patel, A.; Choudhary, M.; Anand, A.; Panchal, H.; Parikh, S. Right cervical lymphadenopathy: A rare presentation of metastatic hepatocellular carcinoma. Gastroenterol. Hepatol. Bed Bench 2014, 7, 177-182.

13. Zeng, J.-X.; Tian, X.; Zhu, H.-L.; Zhang, X.-B.; Luo, Q. A case of hepatocellular carcinoma diagnosed as facial cutaneous metastasis survives for 18 months. Chin. Med. J. 2019, 132, 616-617. [CrossRef] [PubMed]

14. Aldahham, A.; Boodai, S.; Alfuderi, A.; Almosawi, A.; Asfer, S. Abdominal wall implantation of hepatocellular carcinoma. World J. Surg. Oncol. 2006, 4, 72. [CrossRef] [PubMed] 